\title{
Analyzing Involution in the Workplace with Robotic Machine Interference in China: From a Malthusian and a Marxian Perspective
}

\author{
Wenbo Huang ${ }^{1, *}$ \\ ${ }^{1}$ College of Social Science, Michigan State University, East Lansing, Michigan, United States \\ *Corresponding author. Email: huangw54@msu.edu
}

\begin{abstract}
This essay researches the question: What is the effect of involution with robotic machine interference in the workplace? Since 2019, involution in the Chinese workplace was recognized as a serious social problem. At the same time, the rapid population growth and technological development in China exposed a pessimistic trend of involution in the age of AI. In this essay, the effect of involution with robots interference will be analyzed based on the framework of Malthusianism and Marxism by conducting a case study of $\mathrm{C}$ factory in Beijing; a prediction of future trends of involution will also be given at the end of study. Quantitative surveys and qualitative interviews are used in the case study to investigate the effects and relationships between involution and application of robotic machines from a micro perspective. The overall results suggest an intensification of involution with the application of robotic machines based on Marx's perspective in 3 aspects: Robotic production (1) simplifies labor's tasks and improves working efficiency; (2) significantly increases the overtime frequency and length; and (3) increases workers' mental stress in both workplace and daily life. The research leads to several predictions: In the short run, involution will be intensified from the micro perspective and remained uncharted from macro perspective. In the long run, there will be a diminishing trend in involution from a micro perspective, while an intenser involution will be exposed from a macro perspective. This research studies involution from both micro and macro perspective, to offer a wider variety and multiple implications for future researches with a more holistic understanding.
\end{abstract}

Keywords: Involution, Robotic Machines, Malthusianism, Marxism, China, Task Simplification, Working Efficiency, Overtime, Mental Stress.

\section{INTRODUCTION}

This essay researches the question: What is the effect of involution in the workplace with robotic machine interference in the age of AI? In 2019, involution in the workplace became a popular meme on social media in China. With more white and blue collars workers suffering the effects of involution, the government modified the labor law to mitigate the situation. Involution will be one of the central factors in arguments about the interference of AI introduced for simplifying or replacing human labor in the future. Spyros Markridakis analyzed the impact of AI application on societies and companies, emphasizing that AI can destroy middlerange jobs while increasing works on the low and high ends, increasing social inequality as the pay gap between low and high-end jobs grows wider [1]. However, the impacts on involution were left unknown. Alt- hough involution is an abstraction for certain economic and social phenomena that are hard to recognize and measure, few scholars have conducted relevant research. This doesn't mean that involution is insignificant; in fact, involution one of the key obstacles to social change. Although achieving the goal of making fully autonomous AI is still far away due to myriad technological and ethical issues, the prospect of a future society transformed by AI has been clearly recognized. Due to time limitation and feasibility, this essay examines the intensity of involution from a micro perspective and aims to provide an analysis from the perspective of workers who are directly involved in the involution in the workplace.

Early in the 1960s, an agricultural involution in Indonesia was described by Clifford Geertz. According to Geertz, the agricultural culture and technology devel- 
opment in Indonesia were stifled by the focus on modifications in the farming process, the simplification of single peasant's tasks, and complications in the land leasing relationships and labor division preventing technological innovation or structural change in the economy [2]. Although advanced technology had been applied in agriculture to mitigate unemployment by increasing posts in the farmlands, productivity did not improve as expected. Hence, agricultural change was still not capable of triggering an industrial revolution in Indonesia. Moreover, the same phenomenon was recognized in the Qing dynasty in China. Philip C. C. Huang has argued that subsistence agriculture - a form of economic structure for fulfilling the needs rather than making a profit-led to economic stagnation in the Qing dynasty [3]. In such an economy, commercial trade resulted in what Geertz termed "shared poverty" instead of the dynamism of Chinese capitalism. According to Huang, rural revitalization strategies eventually transformed the economy from a subsistence economy to a capitalized economy in rural China, triggering a hidden agricultural revolution and remedied the involution [4].

Involution can happen not only in agricultural fields but also in politics, education, and economics. This research examines the intensity of the involution in the workplace caused by the introduction of AI by focusing on a case in China where various large-scale robotic machines have been introduced in C Factory. The effect of this introduction of robotic production on workers' tasks, overtime, and mental stress will be analyzed based on the framework of Malthusianism and Marxism. Although neither autonomous humanoid workers nor AI has been fully developed thus far, robotic machines have already been begun replacing human workers on factory assembly lines. C Factory, for example, has invested in numerous robotic machines with the aim of improving productivity resulting in hybrid assembly lines composed of both human and robotic workers. This factory provides an ideal case study for this research.

In the case of China, the negative effects brought by involution have been explicitly shown in numerous fields, in which the involution in employment is one of the most obvious and intensest examples. Yi Zhang conducted a statistical survey about the Chinese employment situation in early 2021. According to Zhang, the unemployment rate among 16 to 24 year olds in China has increased from $13.1 \%$ to $13.6 \%$ within one month in 2021 March. Moreover, more than 9 million new graduates will enter the labor market at the end of June; the average work hour in China was 46.9 hours per week, which increased by 2.1 hours compared to March 2020 [5]. These trends will intensify as more machines are applied to the factory assembly lines. Thus, a potential strategy for balancing involution and the application of AI needs to be formulated. Not based on the data alone, but encompassing a comprehensive structural solution that goes to the heart of the involution issue in the age of AI. This research was conducted from the perspective of blue-collar workers in the $\mathrm{C}$ Factory and aimed to examine the effect of involution brought by the application of robotic machines.

This article proceeds as follows. First, to better understand involution and its implications, a literature review focusing on the connections between population growth and the alienation of labor will be introduced to distinguish and define involution from both macro and micro perspectives. Then, the case study illustrating the effects of involution in the context of robotic machine interference in China will be introduced. Three hypotheses will be developed based on both Marx's and Malthus's theoretical frameworks. We will describe a research design, and methodology. The fourth section presents both the quantitative and qualitative analysis of involution with robotic machine interference at a micro-level. The last section predicts a future trend of involution from both Marx's and Malthus's perspectives. It puts the phenomenon of involution into a wider perspective providing a basis for further researches.

\section{THEORETICAL FRAMEWORK \& HY- POTHESIS}

In this section, the explanation of involution will be addressed from the perspective of Malthus and Marx from both macro and micro perspectives. From a macro perspective, involution is a cycle of stagnant development, encompassing only quantitative increase or decrease in production but no structural change resulting from development. At the same time, involution includes the effects of exploitation, resulting in an increase in overtime and mental stress for people [6, 7]. Following the description of the relationship between involution and application of robotic machines, three hypotheses about the effects of robotic production will be developed based on Malthus's and Marx's frameworks.

\subsection{Theoretical Framework}

In Lei's work in 2020, a clear definition of involution was given based on Geertz's cased study in Indonesia. Lei defined involution as a cycle mode of stagnant development with only quantitative increase or decrease but no qualitative change when it reaches a certain stage of development [6]. Although the phenomenon of involution was clearly defined in the article, the principle of involution was not fully laid out. The origin the idea of involution is much earlier than Geertz's work. For example, the industrial revolution was a textbook example of involution from a macro perspective.

The principle of involution is derived from the Malthus's theories of population growth. Thus, involution 
can be seen as a social phenomenon that accompanies a Malthusian catastrophe, an inevitable result of rapid population growth. In his book Principle of Population, Malthus suggests that population naturally increases geometrically, while the resources (job supply, foods, education) are increase only algebraically [8]. These suggest that the population growth rate is continually increasing and will eventually exceed the rate of resource increase triggering the Malthus catastrophe. Under such a situation, Malthus argues that the resource competition within a society will be more intense as people get fewer resources per capita, especially working-class people [8]. Thus, those stuck in the involution need to put more effort to earn the same amount of resources as others do. For example, the education involution in China derives a term called "Jiwa", or "student who goes in an extra mile", means children who take lots of extra curriculums such as painting, dancing, or music to increase competitiveness between peers who apply for the same school. Parents may pay hundreds of or even thousands of yuan for these extra curriculums. However, the position in school may not cost that much initially [9]. This kind of competition exists in education fields and in the workplace after these students graduate; in addition, the application of AI and robotic machines makes this situation even intenser. AI plays the role in the workplace of an invasive alien species in the labor market. The replacement of human labor significantly reduced job opportunities in the market, which intensifies the Malthus catastrophe. Thus, people looking for a job face ever stricter requirements for employment, intensifying competition. In other words, the application of AI results in increasing involution in the workplace.

In the industrial revolution in Britain from 1780 to 1880, the technological boom offered workers more job opportunities in factories [10]. This change led to a rapid increase of social resources mitigating involution since more job opportunities significantly decreases competition within the group. However, it did not erase the problem of involution. The intense use of overtime, meager wages, the use of child labor, and the low quality of living for workers were also the evidence of involution during the industrial revolution from a micro perspective.

From a micro perspective, involution is a form of exploitation. Workers experience an anomaly, extended operating hours with meager wages, and intense mental stress. Marx proposed the surplus value in Value, Price, and Profit, which explained these phenomena, refering to the extra value created by workers in excess of their own labor-cost, which is appropriated by the capitalist as profit when products are sold [7]. In other words, the surplus value can be seen as the profit made by the workers; thus, the more surplus value is made, the more profit the company gets, but the more intense involution exists within the company.
According to Marx, surplus value can be represented in the following formula: Value Produced - Exchange of Labor $=$ Surplus Value.

The value produced can be measured by the value produced in the total operating hours ( 8 hours required operating hour and overtime). The exchange of labor is the value workers receive after work, in other words, wages [7]. Based on this formula, surplus value can be increased by either an increase in the value of what is produced or by a decrease workers' wages. Numerous companies chose to increase the value produced by extending operating hours or making workers process more tasks to increase profits, increasing workers' mental stress. In the case of robotic machines in the factory assembly line, workers' working efficiency could be significantly improved with the help of these machines as tools. Whether the factory extends the operating hours or not, the machine brings a massive improvement in the value produced by labor because of improved working efficiency.

\subsection{Hypotheses}

For the company, the most direct way to improve its profits is to increase productivity, thus, increase surplus value for workers. As mentioned above, one of the methods of increasing value produced is to make workers multitask. The application of $\mathrm{AI} /$ robotic machines in the factory assembly line as a tool is aimed at decreasing the load or even replacing human labor for higher efficiency. The following is Hypothesis 1.

Hypothesis 1: The application of robotic machines on the assembly line simplified labor tasks and improved working efficiency.

Increasing efficiency makes factory workers capable of doing the same task faster, which shortens their operating hours simultaneously. As a result, the overtime frequency and overtime length will be decreased at the same time. The decrease in operating hours is seen as a way of mitigating the exploitation in the factory and decreasing the extent of involution. Thus, Hypothesis 2 is divided into two parts.

Hypothesis 2.1: The application of robotic machines on the assembly line decreases overtime frequency and overtime length due to the improved efficiency.

Hypothesis 2.2: The application of robotic machines on the assembly line decreases the overtime frequency and overtime length due to the simplified tasks.

Since various types of robotic machines simplify the tasks, the numbers of sophisticated technical skills and heavy tasks are decreased, thus lowering the requirements for hiring laborers. This means that worker on the assembly line becomes more replaceable, therefore, more likely to worry about the stability of their jobs and 
future. This is especially the case with less skilled and experienced workers. These worries bring stress to their workplace, and they can address stress in their daily life. So Hypothesis 3 is proposed below, and it is divided into two parts.

Hypothesis 3.1: The application of robotic machines affects workers' mental stress in the factory; it brings fewer impacts to senior workers' mental stress but puts more pressure on newcomers.

Hypothesis 3.2: The application of robotic machines affects workers' mental stress in the factory; it brings fewer impacts to workers with a high level of loads and duties but puts more pressure on those doing simplified tasks.

\section{RESEARCH METHOD}

The study of involution from a macro perspective is limited by time and other variables. The massive target population, hierarchical differences in social institutions, and political issues are all difficult to control for. In addition, the macro perspective on involution focuses on the study of economic change and development. In contrast, the micro perspective on involution involves the quality of life and exploitation within the companies, which can be directly reflected by changes in the workplace [7]. Thus, compared to studying involution from a macro perspective, micro research is more feasible and practical. Moreover, involution has been a longlasting social problem in fast-developing China. Therefore, more reliable and representative data can be gathered in China in a short period compared to some highly developed economies.

\subsection{Case Study of C Factory}

C factory, which was chosen as one of 44 lighthouse networks by the World Economic Forum in 2020, is a diesel and hydrogen engine factory found in 2007 in Beijing [11]. The factory has invested in numerous robotic machines (e.g., ABB, MAG, AVL, and Haosen) to simplify production and replace human labor on the assembly line. At the same time, manual production remained in sophisticated and low burdened posts. Thus, the mixture of automatic and manual labor in the factory provides an ideal sample for the research.

Contact with $\mathrm{C}$ Factory was made through the author's social network. Several requests were sent at the end of April and the beginning of May, 2021. However, the manager was not interested in cooperating with the research because of the confidentiality regulations of the factory and the sensitivity of the research topic in Chinese culture. Eventually, after extensive negotiations, the manager finally made a compromise and allowed research in the factory as long as the factory's and interviewees' names were kept anonymous. In addi- tion, the collection of information about worker's wages and private information such as home addresses were forbidden in both surveys and interviews. Therefore, the prohibition of data on wages meant a revision of data analysis needs.

\subsection{Procedure}

The research was conducted at the end of May (from May 24th to May 28th). The manager chose one of the mixed production lines in the factory based on the research proposal. The first day of research included a visit to the assembly line. Manager L pointed out every machine on the factory assembly line, providing sufficient data for evaluating the work load of each post and categorizing them into different groups. Following the visit to the assembly line, we conducted face-to-face interviews with factory managers in the office.

The survey questions were designed on a WeChat application called Questionnaire. WeChat, the mainstream social media app in China, allows for various functions like phone calls, texts, mobile payments, and calling taxis. The Questionnaire application could be sent as a link in the WeChat group chats, and was able to collect answers automatically. Respondents signed a consent form was before answering 21 questions. The survey asked scaling questions about the effects of robotic machines on their posts, working efficiency, overtime, and mental stress from both work and daily lives. A T/F question was added at the end of the survey asking about the future of posts on the factory assembly line. Personal information such as names, ages, genders, and contact information was asked in the last part of the survey. After interviewing managers on the first day, the survey was modified and sent by WeChat group chat. We received surveys from 267 respondents: 241 male and 26 female workers, ages from 19 to 42 years old, and the working experiences from 1 to 11 years.

In the last two days of research, we conducted a face-to-face semi-structured interview for workers after the quantitative data was collected. Since a semistructured interview question leaves more space for interviewees to narrate their own experience and opinions about the question, providing more perspectives. Six semi-structured interview questions were designed based on the results from the quantitative survey. These were used as evidence complementing the survey results, as shown in Table 1 below. The interview questions mainly asked about workers' working experience, overtime, and sources of their stress. 
Table 1. Interview Questions

\begin{tabular}{|c|c|}
\hline Topic & Question \\
\hline \multirow[t]{2}{*}{$\begin{array}{l}\text { Part } 1 \\
\text { Machines }\end{array}$} & $\begin{array}{l}\text { What is your name and please tell me your working } \\
\text { experience? }\end{array}$ \\
\hline & $\begin{array}{l}\text { What changes do robotic machines bring to your } \\
\text { post? And how? }\end{array}$ \\
\hline \multirow{2}{*}{$\begin{array}{l}\text { Part2 } \\
\text { Overtime }\end{array}$} & What do you do during overtime? \\
\hline & How long does it take? \\
\hline \multirow[t]{2}{*}{$\begin{array}{l}\text { Part3 } \\
\text { Stress }\end{array}$} & $\begin{array}{l}\text { Can you tell me a time that you feel extremely } \\
\text { stressed at work or in daily life? }\end{array}$ \\
\hline & $\begin{array}{l}\text { Can you tell me the different stresses you feel dur- } \\
\text { ing work and daily life? }\end{array}$ \\
\hline
\end{tabular}

Manager L provided a small meeting room for the interview. Ten interviewees from the respondent list were randomly chosen, seven male workers and three female workers. In the following section they are referred to by their alias: Mrs. Wei, Mr. Li, Mr. Sun, Mrs. Tang, Mr. Mao, Mr. Wu, Mr. Xu, Mr. Liu, Mrs. Wang, and Mr. Jia.

\section{RESULTS \& ANALYSIS}

Generally, the results showed a significant dual effect on involution produced by robotic machines. Some effects decreased the intensity of involution, while others significantly intensify the effects of exploitation based on the framework of alienation of labor. Based on the results collected, several T-tests were conducted with IBM SPSS Statistics version 28 to test the correlations between indirectly connected variables.

\subsection{Working Efficiency \& Simplicity.}

The working efficiency and simplicity were directly measured by 2 scaling questions. Table 2 shows the responses patterns to two questions: (1) Does the application of robotic machines improve your productivity per unit? and (2) Does the application of robotic machines simplify your tasks?

Table 2. Attitudes towards working efficiency and task simplicity

\begin{tabular}{|c|c|c|c|c|c|c|}
\hline & & SA & $A$ & $\mathrm{Neu}$ & D & $S D^{*}$ \\
\hline $\begin{array}{l}\text { Machines improve } \\
\text { efficiency }(\mathrm{N}=267)\end{array}$ & working & $\begin{array}{l}24.3 \\
\%\end{array}$ & $\begin{array}{l}48.3 \\
\%\end{array}$ & $\begin{array}{l}24.3 \\
\%\end{array}$ & $\begin{array}{l}2.6 \\
\%\end{array}$ & $\begin{array}{l}0.4 \\
\%\end{array}$ \\
\hline $\begin{array}{l}\text { Machines } \\
(\mathrm{N}=267)\end{array}$ & tasks & $\begin{array}{l}26.2 \\
\%\end{array}$ & $\begin{array}{l}44.2 \\
\%\end{array}$ & $\begin{array}{l}25.1 \\
\%\end{array}$ & $\begin{array}{l}3.7 \\
\%\end{array}$ & $\begin{array}{l}0.7 \\
\%\end{array}$ \\
\hline
\end{tabular}

The interview asked a more detailed question about the efficiency and simplicity to support the results. Mr. Mao, who has worked in the factory for four years as a senior employee, used to work in the manual engine painting department, and currently works at the engine testing post, suggested that the application of robots brings significant changes to productivity improvement by combining painting and drying processes. He stated that there were also some blind spots on the engine that the machine could not reach, so human labor is still required in the painting process. However, it was still much more efficient than before. Mr. Mao also mentioned that the engine testing machine could work independently; all he needed to do was to check the screen's data to see if the engine was running as expected, which allowed him to go back to the painting post and conduct and train newcomers.

Thus, both survey and interview results confirm Hypothesis 1: the application of robotic machines on the assembly line simplified labor's tasks and improved their working efficiency. Therefore, the task simplification and improvements in efficiency bring a positive effect on againsting involution. In later interviews, three main ways to improve the efficiency were being conducted: (1) reducing human labor in complicated and time-consuming tasks; (2) multi-tasking by combining similar tasks (e.g., tightening different bolts or screws, or engine painting and drying); and (3) digitizing information using a common standard. These methods improve workers' efficiency and simplified workers' tasks simultaneously.

\subsection{Overtime}

Table 3. Information of overtime frequency

\begin{tabular}{llllll}
\hline & $\begin{array}{l}3+ \\
\text { time } \\
\mathrm{s}\end{array}$ & 3 & 2 & 1 & 0 \\
& & & & & \\
& & & & & \\
& & & \\
$\begin{array}{l}\text { Overtime frequency per } \\
\text { week }(\mathrm{N}=267)\end{array}$ & $\begin{array}{l}71.2 \\
\%\end{array}$ & $\begin{array}{l}17 \% \\
2 \%\end{array}$ & $\begin{array}{l}5.2 \\
\%\end{array}$ & $\begin{array}{l}4.9 \\
\%\end{array}$ & $\begin{array}{l}1.5 \\
\%\end{array}$
\end{tabular}

\begin{tabular}{lllllll}
\hline \multicolumn{7}{c}{ Table 4. Information of overtime length } \\
\hline $\begin{array}{l}3+ \\
\text { hours }\end{array}$ & $2-3$ & $1-2$ & $0-1$ & 0 \\
\hline $\begin{array}{l}\text { Overtime } \\
\text { length per } \\
\text { day }(\mathrm{N}=267)\end{array}$ & $53.6 \%$ & $39.3 \%$ & $4.1 \%$ & $1.1 \%$ & $1.9 \%$ \\
\end{tabular}

Table 3 and Table 4 show data about overtime, suggest there is still intense use of overtime in the factory following the implementation of robotic machines. $40.07 \%$ of respondents who answered more than 3 times actually worked overtime 6 to 7 times a week. Furthermore, in regard to the length of overtime, 50\% of respondents who chose work more than 3 hours worked more than a total of 12 hours a day. After coding the results of questions about working efficiency, simplicity, and overtime, 2 T-tests were conducted to examine the correlations. The first T-test examined the 
correlation between overtime and task efficiency per unit, and the result showed $\mathrm{p}>0.05$, which suggested no relationships between the working efficiency brought by robots and overtime. Thus, Hypothesis $\mathbf{2 . 1}$ was invalidated. The second test examined overtime and simplicity, and the result showed a correlation of $\mathrm{p}$ $<0.001$, which supports Hypothesis 2.2 suggesting that simplifying tasks was strongly related to the reduction in the use of overtime.

In later interviews, a strong negative correlation between task simplicity and overtime was shown. Several employees mentioned the overtime work was strongly dependent on the extent to which tasks were done by machines. This suggests that the more autonomous a machine is, the more varied tasks they need to take. Thus, the overall frequency and length of overtime had been amplified due to conducting various extra tasks brought by task simplification. Mr. Liu, a 22-year-old worker who benefited from the highly autonomous robot on his post, said that he got two hours of leisure time every day because robots improved productivity and simplified his tasks a lot. However, 8-hours of operating was required. In the time saved he learned group management skills and skills related to other posts. When he talked about the overtime, he pointed out that sometimes he could not finish his extra work like managing group members and familiarizing skills in time, so in the end he worked longer hours to finish those tasks so that he could go home without worries. And he indicated that this situation has become more and more frequent. Moreover, both Mr. Liu and Mr. Wu mentioned everyone needed to stay on the assembly line when the workload increased no matter how efficient the machine. At the same time, on regular days, they would do the maintenances servicing for the robots when no extra tasks have been scheduled. Mr. Liu also said that some robots were so old and mechanically sophisticated (e.g., the ABB piston categorizer and assembler) that they needed to pay attention to carefully servicing those robots, which massively extend their operating hours in the factory.

In the case of Mr. Liu and Mr. Wu, simplified tasks enabled workers to take on more duties, which extended their working hours beyond the eight hours required by law. In other words, the labor demands significantly increased with the application of the robotic machines, both the number of tasks assigned workers, and their working hours. However, since production was based on the numbers of orders, according to Mr. Liu's statement, productivity can remain the same. According to Marx, exploitation and involution were both intensified by the addition of robotic machines to the production line[7].

\subsection{Mental Stress}

Measuring mental health was more challenging than other variables since it is difficult to set a standard. Thus, a scaling question asking about the frequency of feeling stressed was designed in a direct way: How often do you feel stressed? The result was shown in Table 5. Two-T-tests were conducted to test the correlations of mental health, working experience, and physical stress at work. The interview will be used as evidence of the impacts of robotic machines.

\subsubsection{Mental Stress \& Working experience}

Table 5. Attitudes towards mental stress

\begin{tabular}{llllll}
\hline & & $\begin{array}{l}\text { Al- } \\
\text { way } \\
\text { s }\end{array}$ & $\begin{array}{l}\text { Some- } \\
\text { times }\end{array}$ & $\begin{array}{l}\text { Rar } \\
\text { ely }\end{array}$ & $\begin{array}{l}\text { Nev } \\
\text { er }\end{array}$ \\
& & & & & \\
Frequency of feeling & $\begin{array}{l}11.2 \\
\text { stressful (N=267) }\end{array}$ & $31.1 \%$ & & 46. & 10. \\
& & & & $8 \%$ & $9 \%$
\end{tabular}

Table 6. Information of working experiences

$\begin{array}{lllll}\begin{array}{l}7+ \\ \text { Year } \\ \text { s }\end{array} & 5-7 & 3-5 & 1-3 & 0-1 \\ & & & & \\ 8.6 \% & 12 . & 17 . & 51 . & 10 . \\ & 4 \% & 2 \% & 3 \% & 5 \%\end{array}$

$\begin{array}{lllll}\text { in the factory }(\mathrm{N}=267) & 4 \% & 2 \% & 3 \% & 5 \%\end{array}$

Table 6 shows the distribution of workers' working experience in the factory. Based on the data from Table 5 and Table 6, the first T-test examines the correlations between the frequency of feeling stress and working experience in the factory. Both quantitative data were collected during the survey. The result showed $p<0.05$, which suggests a strong relationship between mental stress and working experience. Although the interview shows some individual differences, Hypothesis 3.1 was well supported based on workers' experience in the factory, which will be introduced later.

The interview revealed a difference in mental stress based on their stage of work. Newcomers learning the machine operation and getting familiarized with the factory tend to have more intense mental stress. In contrast, senior workers tend to show a more relaxed attitude to the work. Moreover, Mrs. Wei and Mr. Wang also said that the difficulty in familiarizing machines at the beginning also stressed them out. For example, senior employee Mr. Wang mentioned that the engine testing machine was imported from the US, so the English system made him hard to catch up with the improved efficiency because he needed to learn the language and specialized vocabularies in the system in a short period, which made him stressed out for a long time. But he felt relaxed after he got used to the system, and now he feels no pressure. He said that the machine really helped 
him decrease stress and workload. Moreover, another experienced senior worker Mr. Mao, with four years of experience in the factory, mentioned he was stressed at the beginning because there were some machines he had never seen in his former company, so it took him some time to familiarize himself with the machines. Today, Mr. Mao has become one of the most experienced workers in the factory, and he stated he had no stress for a long time because he earned everything he needs in life. Machine operations were extremely easy for him, so he filled "rarely" in the questionnaire.

According to the interview results, learning the machine operation is one of the biggest challenges for newcomers in the factory, which might generate most of the stresses towards workers. This result supported Hypothesis 3.1. The application of robotic machines does affect workers' mental stress in the factory; it brings fewer impacts to senior workers' mental stress but puts more pressure on newcomers.

\subsubsection{Mental Stress \& Task Simplicity}

Table 7. Attitudes towards physical stress

\begin{tabular}{llllll}
\hline & SA & A & Neu & D & SD* $^{*}$ \\
\hline Long time working & 30. & 40. & 25. & 2.6 & 1.1 \\
makes workers feel & $3 \%$ & $1 \%$ & $8 \%$ & $\%$ & $\%$ \\
fatigued (N=267) & & & & & \\
\hline Scales from strongly agree to strongly disagree
\end{tabular}

Table 7 shows workers' attitudes towards physical stress. We used the second T-test to test the correlation between mental stress and physical stress. The result showed $\mathrm{p}<0.05$, which suggested that there was a relationship between physical stress during operation and mental stress. However, this result does not fully support Hypothesis 3.2 since 7 interviewees from different posts stated that their tasks had no relation with their stress level.

In the question asking about the source of their stress in workers' workplace, Mr. Wu (alias) suggested that he did not feel much stress when installing the flywheel (a manual post requiring certain physical strength and patience). Still, he felt stressed when he delayed the efficiency of the whole production line because slow installation may lead to arguing between workers. He also said that such a situation only happened after lunchtime in the afternoon. He usually felt sleepy after lunch and exhausted after holding the heavy flywheel for a long time. Mrs. Wei, a female newcomer responsible for piston gasket installation (a manual post with a light workload and few duties), had a similar problem as $\mathrm{Mr}$. Wu. She mentioned that she was afraid of delaying the efficiency caused by quality issues at first. She always had a conflict with other employees because of delays and quality issues. Besides, she filled "always" to the question asking the frequency of feeling stress. She thought her work was so easy to learn and handle that she did not think she could stay long in that post because someone could easily replace her with more experience in higher efficiency. In addition, various sources of stress from daily life were brought into the workplace. For example, Mr. Sun's (alias) tasks were significantly simplified by robots, but he said he was very stressed at work because he frequently made mistakes in machine operations. For example, over-relying on muscle memory on simplified tasks made him more fallible when tightening bolts and screws in order. However, his primary stressors were his pregnant wife and housing problems in Beijing. He would have his second baby in October 2021, but he did not have enough vacations to stay in the hospital with his wife. Furthermore, Mr. Sun also mentioned that his wages were not enough for him to rent a regular house for two children and a mother in Beijing.

The interview results did not fully confirm Hypothesis 3.2. On the one hand, workers responsible for some simplified jobs that require fewer skills do suffer from a high level of stress because of the fear of being replaced by others. On the other hand, coworkers' blame or quarrels could also raise the stress level: manual post workers may delay the efficiency of workers who work with robots. Thus, an indirect impact of working conditions is brought on by robotic machines. In addition, the workplace is not the only source of workers' mental stress. In the case of Mr. Mao and Mr. Sun, the quality of life also plays a role in generating mental stress senior workers with more experience and bigger age may feel more relaxed than younger newcomers because of the more stable life. Thus, the mental stress brought by the robotic machines is not fully determined by the task's simplicity. Instead, daily life is also a variable that needs to be considered.

\section{FUTURE TRENDS}

Table 8. Attitudes towards posts in the future

\begin{tabular}{|c|c|c|}
\hline & More & Fewer \\
\hline $\begin{array}{l}\text { The number of posts in the fu- } \\
\text { ture }(\mathrm{N}=267)\end{array}$ & $50.2 \%$ & $49.8 \%$ \\
\hline
\end{tabular}

In the last section of the survey, a question asking about future trends was given to workers to predict the future trends of involution. As illustrated in Table 8, the result showed that 134 people thought there would be more jobs in the future, while 133 people thought there would be fewer, which suggests a strong debate about the future trends in the number of jobs. And a significant difference in opinion was revealed by the interviews. Generally, there were mainly 2 perspectives that made the answer to this question controversial: short run and long run. 


\subsection{Trends in the short run}

In the short run, the factory primarily aims to reduce workers' errors in order to improve productivity by simplifying workers' tasks. According to Fredrick Taylor, the measuring, simplifying, and breaking down of labor's tasks into different parts based on time requirements and individual capability, is an inevitable strategy that leads to increased productivity [12]. This strategy ensures not only product quality but also productivity and efficiency. Since more specialized posts are added to the assembly line, the stress from multi-tasking significantly decreases, and the task simplification is improved. In the interview, the issue of mistakes caused by muscle memory was mentioned by both managers and workers more than four times. Manager L, manager $\mathrm{S}$, and Mr. Sun said that there were various types of engines produced on the same assembly line. Thus workers needed to acquire all knowledge about the engine they worked on. Although there was no significant difference in the engine parts, the parts were designed differently. For example, there were difference in the position and size of piston rings and difference in the order for tightening screws. These tiny differences fatigued workers, who were more prone to mistakes during the installation processes, leading to further quality issues and delay productivity. Thus, work measurement would be an optimal strategy in the short run before investing in more robotic machines. However, this kind of task simplicity based on work measurement produces controversial results in regard to involution

According to Marx's perspective on alienation of labor, the simplification of tasks significantly exploited the surplus value of labor, which was discussed in the sections above [7]. Based on the result analyzed in Section 4.2, the simplified tasks resulting in more extra responsibilities for workers, which raises the surplus value that causes workers to suffer from an intenser extent of involution.

In contrast, the simplification and breaking down of tasks can also be seen as a strategy to increase job supply, which can be seen as an increase in resources that significantly decreases peer competition within the society. Or it can also be seen as an increase of resources in the market for reducing the impact of involution based on Malthus's framework [8]. However, due to the order-oriented business model in the factory, the productivity increase cannot be assured by the task simplification and the increase in posts. Therefore, such an increase in the number of posts may also lead the factory to a situation that is equivalent to the "shared poverty" in Indonesia and "subsistence economy" in the Qing Dynasty, which both represent intense involution. Thus, from a macro perspective, the phenomenon of involution in the short run is closely tied to the business model of the factory.

\subsection{Trends in the Long run}

Most interviewees who thought there would be fewer posts in the future mentioned the age of AI and multifunctional human resources in interviews. A multifunctional human resource stood for people knowledgeable of numerous aspects and specialized in certain fields [13]. Mr. Liu suggested that there was already an obvious trend in the factory that robotic machines would replace the human labor force since he found that the improvement in working efficiency brought by task simplifications and breaking downs was not compatible with the changes brought by robotic machines. And this statement was confirmed later with manager L. He mentioned there would be more and more machines coming into the factory during July and October 2021 to decrease loads on human laborers or replace human labor, which means they were one step closer to the fully automatic assembly line. In the question asking where these workers would go in the future, Mr. Liu answered that he was willing to learn more skills about the factory assembly line in order to find his place in the future and try to be a multi-functional human resource. The answer from managers was more radical compared to the answers from workers. Several managers agreed that there would definitely be a diminishing amount in a number of workers, but whatever they chose, to leave or to stay, it all depended on their skills acquired and the needs of the family. In other words, only those with multifunctional resources and technical skills will be chosen to stay in the factory. Multi-functional human resources, by definition, can optimize the working environment in a shorter period due to skills being equipped. However, for companies, these skills also make them easier to use in various kinds of tasks with less need of training. Hence, multi-functional human resources are more likely to be exploited and suffer from a more intense level of involution in the workplace.

Based on the interview results, using the robotic machine for human labor is a long-run goal of the factory. This suggests that only a few highly skilled workers or even 0 workers will be hired in the long-run future when fully automatic robotic machines run 24/7. According to Marx's framework, the phenomenon of exploitation will be reduced in the long-run since the production process consists of less human labor [7]. Thus involution will not exist anymore along with the exploitation of the worker. However, in a wider context, the application of automatic robots puts workers in the labor market into Geertz's situation: an increase in population in the labor market and a diminishing trend in job supply since AI replaces human labor with higher efficiency and longer operating hours. Therefore, a textbook version of the Malthus catastrophe will be formulated in the age of AI, which increases the unemployment rate and increases peer competition [8]. Moreover, the prevalence of multifunctional human resources in 
the labor market is more compatible with job hunting than those who are only familiar with a single task. Therefore, after the company hires them, those left in the labor market are highly likely to experience stricter and more intense peer competition.

\section{CONCLUSION}

By investigating the $\mathrm{C}$ factory's case, this paper demonstrates that robotic machines have a significant impact on involution. Although workers' task- simplicity and productivity were improved by the addition of robotic machines, more tasks were added to their jobs in both regular operating hours and overtime. This refers to the application of robotic machines that exploit the workers' surplus value, thus, intensifies involution. In addition, the research shows that workers in the factory are suffering from various kinds of stress at a different level, from various sources. Whether the stress was from the robotic machines or daily life, it was a significant signal of involution, which may cause problems on the assembly line. In an empirical study of working stress in the banking sector by Ilamathi et al., the result shows that mental stress from both individual and organizational levels impacts employees' productivity.

Involution is by no means a simple term that describes social phenomena in a certain society in a certain period of time; rather, it always accompanies social development. In addition, its affect on social development disregards the extent of development and the forms of economy. Its impact on societies cannot be simply examined from statistical data from a macro perspective since the individuals are the primary victims of involution [8]. Thus, it is a valuable topic for the scholar to research, especially in the future. With more and more advanced AI being developed, resources for humans such as job opportunities and natural resources will be significantly reduced, resulting in the intensifying Malthus catastrophe.This it is a practical topic that is worthy of being considered in the fields of company management and policy-making.

Although the effect robotic machine interference on industrial involution has been revealed, several drawbacks caused by various limitations were discovered after the research. The first problem is the issue of perspective. This essay examines the involution mainly from Marx's theoretical framework, which leaves some blind spots in the macro perspective. Due to the confidential regulations from the factory, detailed information about workers such as wages and educational background were studied in the survey and interviews. Thus, a more detailed insight of involution with the interference of robotic machines could not be collected and analyzed. Furthermore, the division of labor based on gender also plays a role that affects the involution. However, due to the limitation of time and the theoreti- cal work applied, no further tests and analyses have been conducted from a gender perspective.

In future research, it is necessary to gather information like wages and educational background in surveys and interviews, as these data are helpful in viewing involution in micro perspective. Moreover, the power of the female in the workplace has long been a concern in many studies and, involution and the application of robotic machines may well have a distinctive impact on female workers.

\section{REFERENCES}

[1] Makridakis, Spyros. "The forthcoming Artificial Intelligence (AI) revolution: Its impact on society and firms." Futures 90, 2017: 46-60.

[2] Geertz, Clifford. Agricultural involution. University of California Press, 2020: 83-102, 124.

[3] Huang, Philip CC. "The Peasant Family and Rural Development in the Yangtzi Delta, 1350-1988: A Reply to Ramon Myers.”, 1991: 629-633.

[4] Huang, Philip CC. "China's hidden agricultural revolution, 1980-2010, in historical and comparative perspective." Modern China 42.4, 2016: 339-376.

[5] Yi, Zhang. "The employment situation remains stable" (2021). Chinese Information News, 2021: 1.

[6] Kang, Lei, and Yeyao Jin. "A review of involution and its psychological interpretation." Filozofia Publiczna i Edukacja Demokratyczna 9.1, 2020: 728.

[7] Marx, Karl. "Value, price, and profit." Vol. 5. CH Kerr \& Company, 1910.

[8] Malthus, Thomas. "An essay on the principle of population" (1798). Yale University Press, 2013: 8,10 .

[9] Xin, Guan. "How can we be 'willing' in the education involution?” Xinhua News, 2021.

[10] Mokyr, Joel. "Entrepreneurship and the industrial revolution in Britain." The invention of enterprise. Princeton University Press, 2012. 183-210.

[11] Wen, Wu. "Digital push! Stand out from thousands of factories around the world, FC was awarded the title of 'Lighthouse network'." chinatruck.org, 2020.

[12] Taylor, Frederick Winslow. Scientific management. Routledge, 2004.

[13] Wu, Defu, Sun, Deliang, Zhang, Xinyuan. "Multifunctional human resources and self study tests." Chinese Adult Education, 1993. 1. 
[14] Ilamathi, M., and M. Uma Raman. "The impact of workplace stress acts as a predictors on employee's productivity and efficiency-An empirical study in banking sector with reference to private and public sector banks." Elementary Education Online 20.5, 2021: 3452-3459. 